\title{
STUDY ON BEHAVIOR OF CONCRETE FILLED ELLIPTICAL STEEL TUBE MEMBERS PART II : UNDER BENDING AND ECCENTRIC COMPRESSION
}

\author{
Xiaoxiong Zha ${ }^{1,}{ }^{*}$, Guobin Gong ${ }^{2}$ and Xichao Liu ${ }^{2}$ \\ ${ }^{1}$ Shenzhen Graduate School, Harbin Institute of Technology, Shenzhen 518055, China \\ 2 Shenzhen Graduate School, Harbin Institute of Technology, Shenzhen 518055, China \\ *(Corresponding author: E-mail: zhaxx@hit.edu.cn)
}

Received: 28 April 2011; Revised: 17 February 2012; Accepted: 29 February 2012

\begin{abstract}
In this paper, based on the ideology of "unified theory", the theoretical calculation equations of ultimate flexural capacity for concrete filled elliptical steel tube members (CFEST) around long and short axes are derived and compared with and verified by finite element simulations. Modified equations are then proposed for practical applications on the basis of the flexural capacity for circular concrete filled steel tube members. Under the guidance of "unified theory" and parametric analysis, the simplified practical calculation equations of capacity for CFEST members under eccentric compression are obtained, and mechanical behavior of a series of CFEST members with different section dimensions is conducted using finite element analysis.
\end{abstract}

Keywords: Elliptical concrete filled steel tube, Unified theory, Bending, Eccentric compression, Finite element, Parametric analysis

\section{INTRODUCTION}

In the framework of "unified theory" proposed by Zhong [1], the concrete filled steel tube (CFST) can be considered to be one unified material, on which the unified capacity is based rather than the simple superposition of capacity of concrete and steel tube. In other words, the unified compressive strength can be expressed by one parameter $f_{\mathrm{sc}}^{\mathrm{y}}$, which incorporates the effect of the concrete-steel interaction. According to ultimate balance theory, the ultimate flexural bending capacity is derived for CFEST members around strong and weak axes. Then the theory is modified and amended with the help of finite element simulation results, and simplified equations are obtained for ultimate flexural bending capacity for CFEST members. Based on the existing interaction equation of $N / N_{0} \sim M / M_{0}$ for flexural capacity for concrete filled circular steel tube, a series of flexural members are analyzed by using finite element simulations for different elliptical aspect ratios. And interaction equations of $N / N_{0} \sim M / M_{0}$ are obtained for the CFEST members.

\section{FINITE ELEMENT SIMULATION OF CFEST FOR COMPRESSIVE AND FLEXURAL MEMBERS}

A general-purpose finite element software ABAQUS is used for simulating CFEST members. Solid elements are used for both steel tube and concrete, and the nodes are tied together, i.e. no sliding. The concrete damaged plasticity model is employed for concrete material. The concrete axial compressive stress-strain relation is shown in Figure 1, and the mathematical equation of expression can be described as follows. More details can be found in GB50010 [2]

when $\varepsilon \leq \varepsilon_{\mathrm{e}}, \sigma=E_{\mathrm{c}} \varepsilon, E_{\mathrm{c}}=0.3 f_{\mathrm{ck}} / \varepsilon_{\mathrm{e}}$;

when $\varepsilon_{\mathrm{e}} \leq \varepsilon \leq \varepsilon_{\mathrm{c}}, \sigma=f_{\mathrm{ck}}\left[\alpha_{\mathrm{a}}\left(\frac{\varepsilon}{\varepsilon_{\mathrm{c}}}\right)+\left(3-2 \alpha_{\mathrm{a}}\right)\left(\frac{\varepsilon}{\varepsilon_{\mathrm{c}}}\right)^{2}+\left(\alpha_{\mathrm{a}}-2\right)\left(\frac{\varepsilon}{\varepsilon_{\mathrm{c}}}\right)^{3}\right]$; 
when $\varepsilon_{\mathrm{c}} \leq \varepsilon \leq \varepsilon_{\mathrm{u}}, \sigma=f_{\mathrm{ck}} \frac{\varepsilon / \varepsilon_{\mathrm{c}}}{\alpha_{\mathrm{d}}\left(\varepsilon / \varepsilon_{\mathrm{c}}-1\right)^{2}+\varepsilon / \varepsilon_{\mathrm{c}}}$;

where:

$\varepsilon_{\mathrm{e}}$ - compressive strain corresponding to stress with the value of $0.3 f_{\mathrm{ck}}$ at hardening stage

$\varepsilon_{\mathrm{c}}$ - compressive strain corresponding to stress with the peak value of $f_{\mathrm{ck}}$

$\varepsilon_{\mathrm{c}}$ - compressive strain corresponding to stress with the value of $0.5 f_{\mathrm{ck}}$ at softening stage

$\alpha_{\mathrm{a}}, \alpha_{\mathrm{d}}-$ model constants

The axial tensile stress-strain relationship is based on energy criterion of concrete, i.e. softened stress-fracture energy relation and the stress-strain curve is shown in Figure 2, with the mathematical equation of expression described as follows. $G_{\mathrm{f}}$ and $\sigma_{\mathrm{t} 0}$ are concrete fracture energy (the energy required to cause one continuous crack per unit area), and failure stress respectively. When $f_{\mathrm{ck}}=20 \mathrm{MPa}, G_{\mathrm{f}}=40 \mathrm{~N} / \mathrm{m}$; when $f_{\mathrm{ck}}=40 \mathrm{MPa}, G_{\mathrm{f}}=120 \mathrm{~N} / \mathrm{m}$, and the values of $G_{\mathrm{f}}$ can be obtained using linear interpolation corresponding to other values of $f_{\mathrm{ck}}$.

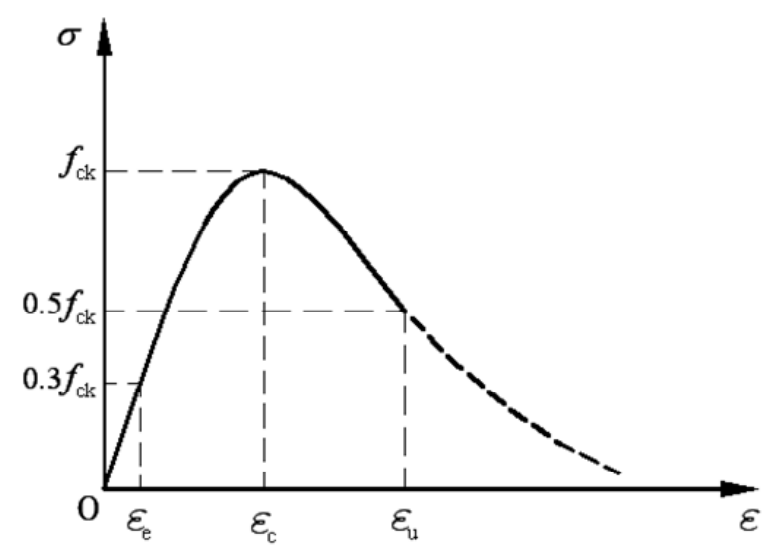

Figure 1. Concrete Compressive Stress-strain Relation of concrete

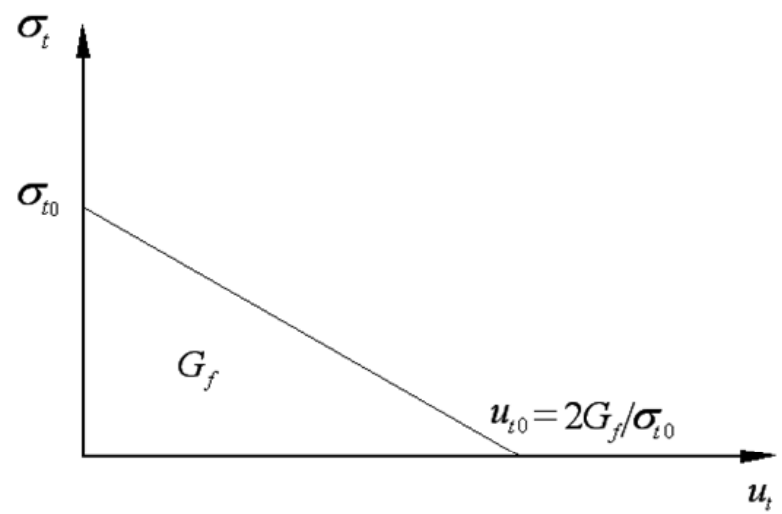

Figure 2. Concrete Tensile Softening Model of concrete 


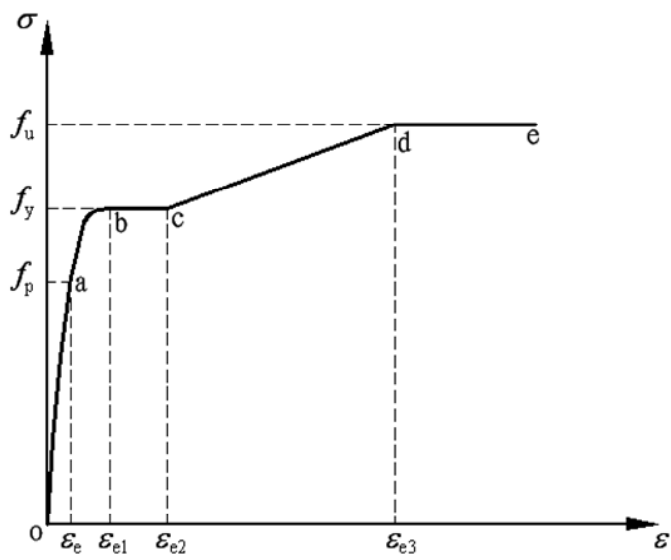

Figure 3. Steel Stress-strain Relation of steel

Axial stress-strain relation of steel is shown in Figure 3, and the mathematical expression can be described as follows :

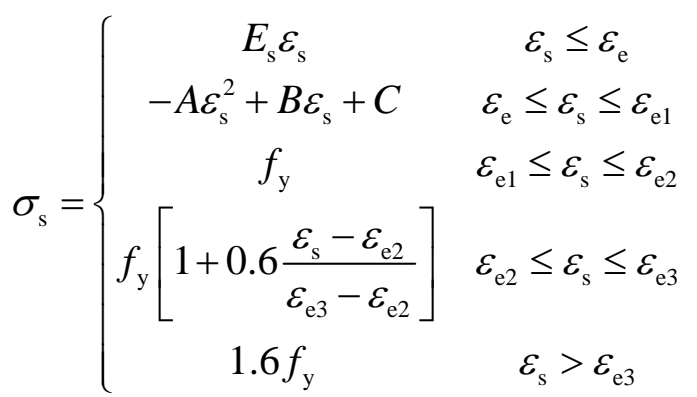

where,

$f_{\mathrm{p}}$ is proportional limit value of steel

$f_{\mathrm{y}}$ is yield strength value of steel

$f_{\mathrm{u}}$ is ultimate strength value of steel

$\varepsilon_{\mathrm{e}}=0.8 f_{\mathrm{y}} / E_{\mathrm{s}}, \varepsilon_{\mathrm{e} 1}=1.5 \varepsilon_{\mathrm{e}}, \varepsilon_{\mathrm{e} 2}=10 \varepsilon_{\mathrm{e} 1}, \varepsilon_{\mathrm{e} 3}=100 \varepsilon_{\mathrm{e} 1}, B=2 A \varepsilon_{\mathrm{e} 1}$,

$A=0.2 f_{\mathrm{y}} /\left(\varepsilon_{\mathrm{e} 1}-\varepsilon_{\mathrm{e}}\right)^{2}, C=0.8 f_{\mathrm{y}}+A \varepsilon_{\mathrm{e}}{ }^{2}-B \varepsilon_{\mathrm{e}}$.

and the details can be found in Han [3].

Figure 4 shows an established CFEST finite element model with solid elements for steel and concrete and there are three layers of meshed elements along the steel tube thickness direction.

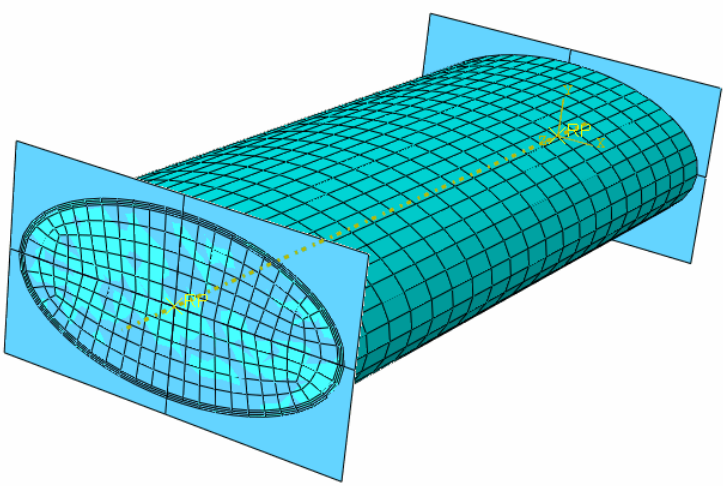

Figure 4. Finite Element Model for CFEST 
In order to verify the accuracy of the finite element model, concrete filled steel circular tube for eccentric compression is simulated using finite element in Chen et al. [4] and Yu and Ding [5], and the simulation results agree well with the test results, see Liu [6].

\section{THE FLEXURAL BEHAVIOR AROUND THE LONG/WEAK AXIS OF CONCRETE FILLED ELLIPTICAL STEEL TUBE}

\subsection{Theoretical Equation Derivation of Flexural Bending Capacity around Long Axis}

All the derivations in this paper are limited to uniaxial bending only. The stress distribution of CFEST at limit state, and the cross section dimensions are shown in Figure 5.

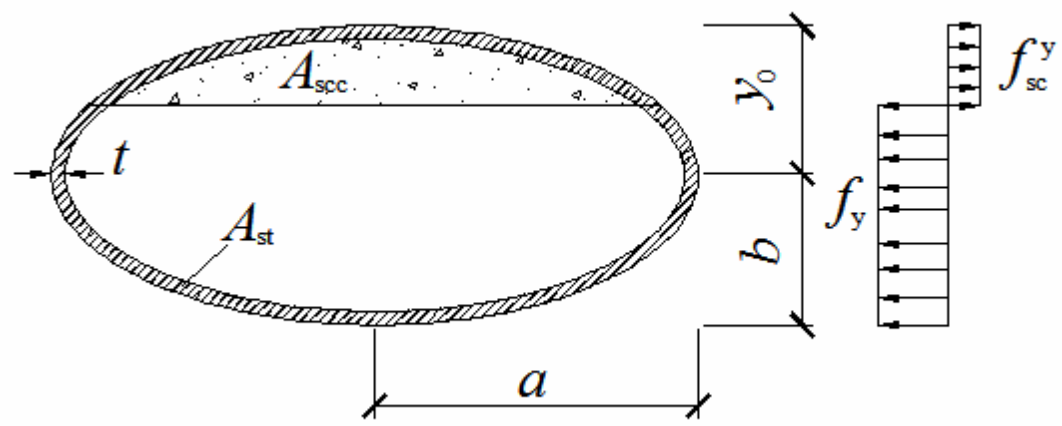

Figure 5. Stress Distribution Bent Around Long Axis for CFEST at Limit State and Section Dimensions

When the member is at limit state, the section stress distribution is as shown in Figure 5. According to static equilibrium, the location of neutral axis can be determined, i.e. y0 (distance of the section centroid to neutral axis).

- $\sum N=0=>$

$$
A_{\mathrm{st}} f_{\mathrm{y}}-A_{\mathrm{scc}} f_{\mathrm{sc}}^{\mathrm{y}}=0
$$

$$
\begin{aligned}
A_{\mathrm{st}}= & \pi a b-\pi(a-t)(b-t)-2 a b\left[\frac{\pi}{4}-\frac{1}{2} \arcsin \left(\frac{y_{0}}{b}\right)-\frac{y_{0}}{2 b} \sqrt{1-\left(\frac{y_{0}}{b}\right)^{2}}\right] \\
& +2(a-t)(b-t)\left[\frac{\pi}{4}-\frac{1}{2} \arcsin \left(\frac{y_{0}}{(b-t)}\right)-\frac{y_{0}}{2(b-t)} \sqrt{1-\left(\frac{y_{0}}{(b-t)}\right)^{2}}\right] \\
A_{\mathrm{scc}} & =2 a b\left[\frac{\pi}{4}-\frac{1}{2} \arcsin \left(\frac{y_{0}}{b}\right)-\frac{y_{0}}{2 b} \sqrt{1-\left(\frac{y_{0}}{b}\right)^{2}}\right]
\end{aligned}
$$

where $\quad A_{\mathrm{st}}$ - section area for steel tube in tension zone;

$A_{\mathrm{scc}}$ - combined section area in compression zone

$a$-half length of long axis for elliptical section

$b$-half length of short axis for elliptical section

$t$-steel tube thickness

$y_{0}$ - distance of the section centroid to neutral axis.

$f_{\mathrm{y}}$ - yield strength of steel 


\section{$f_{\mathrm{sc}}^{\mathrm{y}}$ — combined characteristic strength for concrete filled steel tube}

According to the location of neutral axis based on Eq. 1, the limit bending moment capacity can be obtained by taking moment about the neutral axis contributed by tensile stress and compressive stress:

$$
\begin{aligned}
M_{0}= & M_{\mathrm{s}}+M_{\mathrm{sc}} \\
M_{\mathrm{s}}= & 2 f_{\mathrm{y}}\left\{\left[\frac{\pi}{4} a b y_{0}+\frac{1}{2} a b y_{0} \arcsin \left(\frac{y_{0}}{b}\right)+\frac{1}{3} a b^{2} \sqrt{1-\left(\frac{y_{0}}{b}\right)^{2}}\right.\right. \\
& \left.+\frac{1}{6} a y_{0}^{2} \sqrt{1-\left(\frac{y_{0}}{b}\right)^{2}}\right]-\left[\frac{\pi}{4}(a-t)(b-t) y_{0}+\frac{1}{2}(a-t)(b-t) y_{0} \arcsin \left(\frac{y_{0}}{b-t}\right)\right. \\
& \left.\left.+\frac{1}{3}(a-t)(b-t)^{2} \sqrt{1-\left(\frac{y_{0}}{b-t}\right)^{2}}+\frac{1}{6}(a-t) y_{0}^{2} \sqrt{1-\left(\frac{y_{0}}{b-t}\right)^{2}}\right]\right\} \\
M_{\mathrm{sc}} & =2 f_{\mathrm{sc}}^{\mathrm{y}}\left\{\frac{1}{3} a b^{2}\left[1-\left(\frac{y_{0}}{b}\right)^{2}\right]^{\frac{3}{2}}-a b y_{0}\left[\frac{\pi}{4}-\frac{1}{2}\left(\frac{y_{0}}{b}\right) \sqrt{1-\left(\frac{y_{0}}{b}\right)^{2}}-\frac{1}{2} \arcsin \left(\frac{y_{0}}{b}\right)\right]\right\}
\end{aligned}
$$

As the tension strength of concrete is ignored in the above derivation, the actual limit bending capacity will be larger than calculated by Eq. 4. By comparison with finite element analysis results, the bending capacity of CFEST can be approximately expressed as follows:

$M=1.2 M_{0}$

From Eqs. 4, 5, 6, we know that the factors affecting the limit flexural capacity for CFEST are mainly steel strength, concrete compressive strength and member section shape. In order to verify the applicability of the theoretical Eq. 5 to 7, a total of 77 finite element models are established and the results are compared with those from the equations, with an average of 1.004 and variance of 0.0008 , see Liu [6].

\subsection{Practical Equation of Flexural Bending Capacity around Long Axis}

Comparison of theoretical results and finite element simulation results indicates that the limit state equilibrium based limit state flexural capacity for concrete filled steel tube can be reasonably used to calculate the limit flexural capacity. However, the solution procedures are quite complex and not applicable to practical engineering. With finite element analysis results, an equation of flexural bending capacity around long axis for practical purpose is obtained as follows:

$$
\begin{aligned}
& M=\gamma_{\mathrm{m}} W_{\mathrm{sc}} f_{\mathrm{sc}}^{\mathrm{y}} \\
& \gamma_{\mathrm{m}}=-0.4832 k \xi+1.9264(k \xi)^{0.5}
\end{aligned}
$$


where

$\gamma_{\mathrm{m}}$ is cross section plastic development coefficient

$W_{\mathrm{sc}}$ is modulus of the combined section

$\mathrm{k}$ is confining adjustment factor, when around long axis,

$$
k=(a / b)^{0.12}
$$

The comparison of finite element simulation results and Eq. 8 shows that an average of 1.017 and variance of 0.004, see Appendix 2 and also Liu [6]. Compared with Eq. 7, Eq. 8 gives a relatively little larger value, but the equation form is simplified, which is more suitable for practical engineering.

\section{THE FLEXURAL BEHAVIOR AROUND THE SHORT/STRONG AXIS OF CFEST [7-9]}

\subsection{Theoretical Derivation of Flexural Bending Capacity around Short Axis}

The stress distribution of CFEST at limit state, and the cross section dimensions are shown in Figure 5. $\mathrm{y}_{0}$ is the distance of the section centroid to neutral axis.

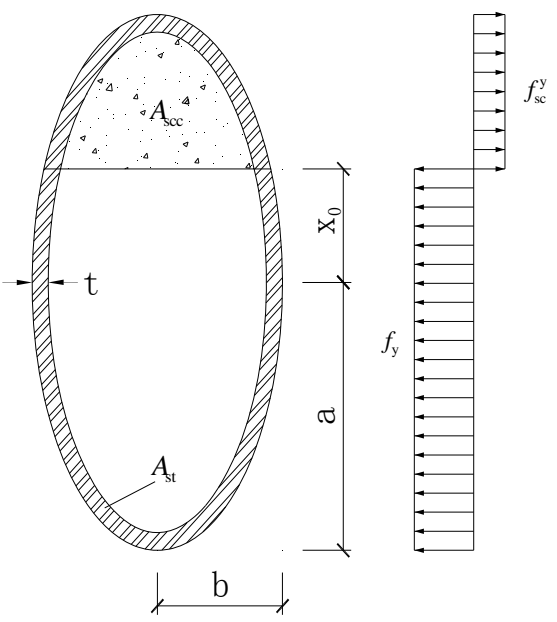

Figure 6. Stress Distribution Bent around Short Axis for CFEST at Limit State and Section Dimensions

When the member is at limit state, the section stress distribution is as shown in Figure 6. According to static equilibrium, the location of neutral axis can be determined, i.e. $\mathrm{x}_{0} \cdot \sum N=0=>$

$$
A_{\mathrm{st}} f_{\mathrm{y}}-A_{\mathrm{scc}} f_{\mathrm{sc}}^{\mathrm{y}}=0
$$

$$
\begin{aligned}
A_{\mathrm{st}}= & \pi a b-\pi(a-t)(b-t)-2 a b\left[\frac{\pi}{4}-\frac{1}{2} \arcsin \left(\frac{x_{0}}{a}\right)-\frac{x_{0}}{2 a} \sqrt{1-\left(\frac{x_{0}}{a}\right)^{2}}\right] \\
& +2(a-t)(b-t)\left[\frac{\pi}{4}-\frac{1}{2} \arcsin \left(\frac{x_{0}}{(a-t)}\right)-\frac{x_{0}}{2(a-t)} \sqrt{1-\left(\frac{x_{0}}{(a-t)}\right)^{2}}\right]
\end{aligned}
$$




$$
A_{\mathrm{scc}}=2 a b\left[\frac{\pi}{4}-\frac{1}{2} \arcsin \left(\frac{x_{0}}{a}\right)-\frac{x_{0}}{2 a} \sqrt{1-\left(\frac{x_{0}}{a}\right)^{2}}\right]
$$

According to the location of neutral axis based on Eq. 10, the limit bending moment capacity can be obtained by taking moment about the neutral axis contributed by tensile stress and compressive stress:

$$
\begin{aligned}
M_{0}= & M_{\mathrm{s}}+M_{\mathrm{sc}} \\
M_{\mathrm{s}}= & 2 f_{\mathrm{y}}\left\{\left[\frac{\pi}{4} a b x_{0}+\frac{1}{2} a b x_{0} \arcsin \left(\frac{x_{0}}{a}\right)+\frac{1}{3} b a^{2} \sqrt{1-\left(\frac{x_{0}}{a}\right)^{2}}\right.\right. \\
& \left.+\frac{1}{6} b x_{0}^{2} \sqrt{1-\left(\frac{x_{0}}{a}\right)^{2}}\right]-\left[\frac{\pi}{4}(a-t)(b-t) x_{0}+\frac{1}{2}(a-t)(b-t) x_{0} \arcsin \left(\frac{x_{0}}{a-t}\right)\right. \\
& \left.\left.+\frac{1}{3}(b-t)(a-t)^{2} \sqrt{1-\left(\frac{x_{0}}{a-t}\right)^{2}}+\frac{1}{6}(b-t) x_{0}^{2} \sqrt{1-\left(\frac{x_{0}}{a-t}\right)^{2}}\right]\right\} \\
M_{\mathrm{sc}} & =2 f_{\mathrm{sc}}^{\mathrm{y}}\left\{\frac{1}{3} b a^{2}\left[1-\left(\frac{x_{0}}{a}\right)^{2}\right]^{\frac{3}{2}}-a b x_{0}\left[\frac{\pi}{4}-\frac{1}{2}\left(\frac{x_{0}}{a}\right) \sqrt{1-\left(\frac{x_{0}}{a}\right)^{2}}-\frac{1}{2} \arcsin \left(\frac{x_{0}}{a}\right)\right]\right\}
\end{aligned}
$$

By finite element analysis, the bending capacity of CFEST can be approximately expressed as follows:

$$
M=1.17 M_{0}
$$

The theoretical results are compared with those from finite element simulations, with an average of 1.003 and variance of 0.0003 , see Liu [6].

\subsection{Practical Flexural Bending Capacity around Short Axis}

Comparison of theoretical results and finite element simulation results indicates that the limit state equilibrium based limit state flexural capacity for concrete filled steel tube can reasonably used to calculate the limit flexural capacity. However, the solution procedures are quite complex and not applicable to practical engineering. With finite element analysis results, an equation of flexural bending capacity around long axis for practical purpose is obtained as follows:

$$
\begin{aligned}
& M=\gamma_{\mathrm{m}} W_{\mathrm{sc}} f_{\mathrm{sc}}^{\mathrm{y}} \\
& \gamma_{\mathrm{m}}=-0.4832 k \xi+1.9264(k \xi)^{0.5}
\end{aligned}
$$


where

$\gamma_{\mathrm{m}}$ is cross section plastic development coefficient

$W_{\mathrm{sc}}$ is modulus of the combined section

$\mathrm{k}$ is confining adjustment factor, when around short axis,

$$
k=(b / a)^{0.6} \text {. }
$$

The comparison of finite element simulation results and Eq. 17 shows that an average of 0.993 and variance of 0.006, see Appendix 3 and also Liu [6]. Compared with Eq. 16, Eq. 17 gives a relatively little smaller value, but the equation form is simplified, which is more suitable for practical engineering.

\section{INTERACTION EQUATIONS OF ECCENTRIC COMPRESSION CAPACITY FOR CFEST MEMBERS [9-11]}

The actions of compression and bending moment on compressive and flexural member may be caused by different loads, i.e. pressure and bending moment can be two independent variables. For the one-way compressive flexural/bending structures, there are mainly three different loading paths, as shown in Figure 7 [3].

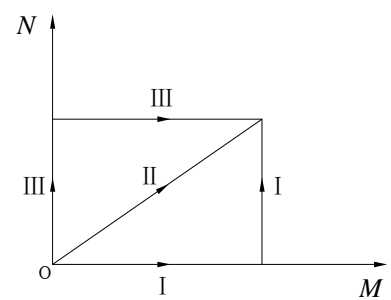

Figure 7. Loading Paths for Compressive and Flexural Member

In this paper, loading path II is adopted for finite element simulation of concrete filled elliptical steel tube, and the main concern is to analyze the concrete filled elliptical steel tube behavior with different cross sections and under different eccentricities.

\subsection{Interaction Equations of Eccentric Compression Capacity around Long Axis for CFEST Members}

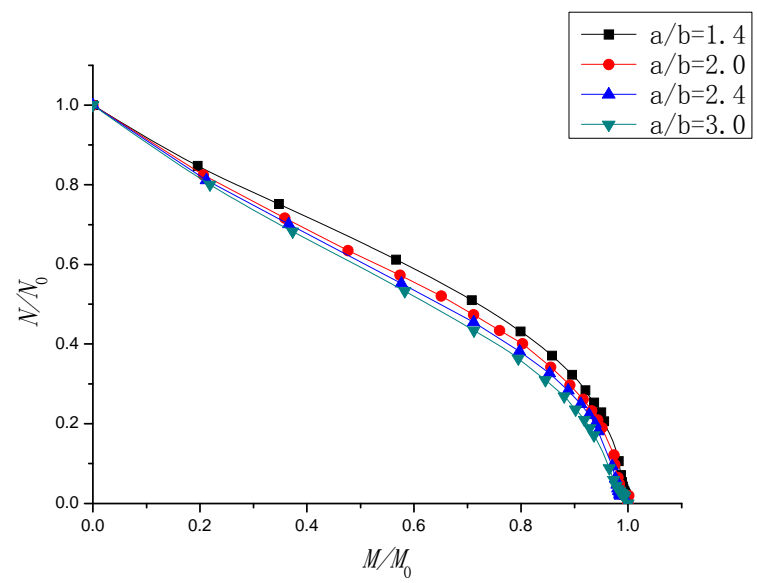

Figure 8. $N / N_{0} \sim M / M_{0}$ of Eccentric Compression Capacity around Long Axis for Concrete Filled Elliptical Steel Tube 
In this paper, finite element analysis is used for obtaining the $N / N_{0} \sim M / M_{0}$ interaction curves. In Figure 8, there are balanced points in the curve of $N / N_{0} \sim M / M_{0}$, which moves down as the increase of steel ratio. Considering that limited value range for the steel ratio, the balanced points are different curves are unified to one point $N / N_{0}=0.2$ [2]. The interaction curve is divided to two segments. Curve fitting is used for obtaining the equation. Considering safety factors, modification factor is introduced and the final interaction equations of eccentric compression capacity around long axis for CFEST is as follows

1) when $\frac{N}{\varphi A_{\mathrm{sc}}} \geq 0.2 f_{\mathrm{sc}}^{y}$

$\frac{N}{N_{0}}+\frac{\beta_{\mathrm{m}} M}{1.32\left(1-0.4 N / N_{\mathrm{E}}\right) M_{0}} \leq 1$

2) when $\frac{N}{\varphi A_{s c}}<0.2 f_{\mathrm{sc}}^{\mathrm{y}}$

$$
-\frac{N}{7 N_{0}}+\frac{\beta_{\mathrm{m}} M}{\left(1-0.4 N / N_{\mathrm{E}}\right) M_{0}} \leq 1
$$

\subsection{Interaction Equations of Eccentric Compression Capacity around Short Axis for CFEST Members}

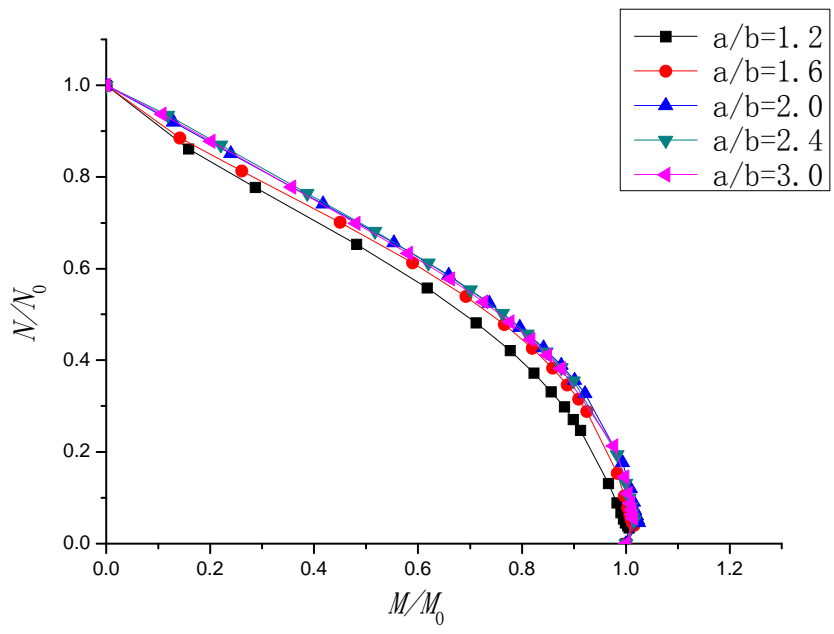

Figure 9. $N / N_{0} \sim M / M_{0}$ of Eccentric Compression Capacity around Short Axis for Concrete Filled Elliptical Steel Tube

Finite element analysis is used for obtaining the $N / N_{0} \sim M / M_{0}$ interaction curves as shown in Figure 9. Curve fitting is used for obtaining the equation. Considering safety factors, modification factor is introduced and the final interaction equations of eccentric compression capacity around short axis for CFEST is as follows

1) when $\frac{N}{\varphi A_{s c}} \geq 0.2 f_{s c}^{y}$

$\frac{N}{N_{0}}+\frac{\beta_{\mathrm{m}} M}{1.45\left(1-0.4 N / N_{\mathrm{E}}\right) M_{0}} \leq 1$ 
2) when $\frac{N}{\varphi A_{\mathrm{sc}}}<0.2 f_{\mathrm{sc}}^{\mathrm{y}}$

$-\frac{N}{7 N_{0}}+\frac{\beta_{\mathrm{m}} M}{\left(1-0.4 N / N_{\mathrm{E}}\right) M_{0}} \leq 1$

\section{CONCLUDING REMARKS}

In this paper the limit equilibrium method is used to derive theoretical bending capacity equation for elliptical concrete filled steel tube members under uniaxial bending, and the equation based results are compared with and verified by the finite element simulation results. In view of complexity in the theoretical equations, modifications are made and simplified and practical equations are obtained which are suitable for practical engineering and also verified by finite element simulation analysis.

For eccentric compression members of concrete filled steel tubes, a series of elliptical cross section, around long and short axis eccentric compression models are established based on finite element analysis. The interaction curves $N / N_{0} \sim M / M_{0}$ are obtained by finite element simulations. Finally, according to the $N / N_{0} \sim M / M_{0}$ curves for different elliptical section dimensions and for different eccentricities around long and short axes, equations are obtained which can be applied to practical engineering.

\section{REFERENCES}

[1] Zhong, S T., "Unified Theory of Concrete Filled Steel Tube - Theoretical Research and Application”, Tsinghua University Press, 2006 (in Chinese)

[2] GB50010-2002, Code for Design of Concrete Structures. Ministry of Construction, People’s Republic of China. (in Chinese)

[3] Han, L.H., "Concrete Filled Steel Tube Structure - Theory and Practice”, Science Press. 2004 (in Chinese)

[4] Chen, B.C., Ou, Z.Q., Wang, L.Y. and Han, L.H., "Eccentric Bearing Capacity Analysis of Concrete Filled Steel Tube”, 2002, Vol. 30, No. 6, pp. 838-844 (in Chinese).

[5] Yu, Z.W. and Ding, X.F., "Mechanical Properties of Concrete Filled Circular Steel Tube Eccentric Loaded Columns”, 2008, Vol. 21, No. 1, pp. 40-46 (in Chinese).

[6] Liu, X.C., "Study of Basic Properties of Concrete Filled Elliptical Steel Tube", Master Thesis, Harbin Institute of Technology Shenzhen Graduate School, 2010, Vol. 6 (in Chinese).

[7] Yang, H., Lam, D. and Gardner, L., “Testing and Analysis of Concrete-filled Elliptical Hollow Sections”, Engineering Structures, 2008, Vol. 30, No. 2, pp. 3771-3781.

[8] Eiichi Inai, Akiyoshi Mukai, Makoto Kai, Hiroyoshi Tokinoya, Toshiyuki Fukumoto, Koji Mori6, "Behavior of Concrete-Filled Steel Tube Beam Columns", ASCE, Journal of Structural Engineering, 2004, Vol. 130, No. 2, pp. 189-202.

[9] Chan, T.M. and Gardner, L., "Flexural Buckling of Elliptical Hollow Section Columns", ASCE, Journal of Structural Engineering, 2009, Vol. 135, No. 5, pp. 546-557.

[10] Amit, H., Varma, James M., Ricles, Richard Sause, Lu, L.W., "Experimental Behavior of High Strength Square Concrete-Filled Steel Tube Beam-Columns”, ASCE, Journal of Structural Engineering, 2002, Vol. 128, No. 3, pp. 309-318.

[11] Toshiaki Fujimoto, Akiyoshi Mukai, Isao Nishiyama, Kenji Sakino, "Behavior of Eccentrically Loaded Concrete-Filled Steel Tubular Columns”, ASCE, Journal of Structural Engineering, 2004, Vol. 130, No. 2, pp. 203-212. 


\section{Appendix 1: Notations}

$\varepsilon_{\mathrm{e}}: \quad$ compressive strain corresponding to stress with the value of $0.3 f_{\mathrm{ck}}$ at hardening stage

$\varepsilon_{\mathrm{c}}$ : compressive strain corresponding to stress with the peak value of $f_{\mathrm{ck}}$ or $0.5 f_{\mathrm{ck}}$ at softening stage

$\alpha_{\mathrm{a}}, \alpha_{\mathrm{d}}$ : model constants

$f_{\mathrm{p}}$ : $\quad$ proportional limit value of steel

$f_{\mathrm{y}}$ : $\quad$ yield strength value of steel

$f_{\mathrm{u}}: \quad$ ultimate strength value of steel

$A_{\mathrm{st}}: \quad$ section area for steel tube in tension zone

$A_{\mathrm{scc}}: \quad$ combined section area in compression zone

$a: \quad$ half length of long axis for elliptical section

$b$ : half length of short axis for elliptical section

$t: \quad$ steel tube thickness

$y_{0}$ : distance of the section centroid to neutral axis.

$f_{\mathrm{sc}}^{\mathrm{y}}$ : combined characteristic strength for concrete filled steel tube

$\gamma_{\mathrm{m}}$ : cross section plastic development coefficient

$W_{\text {sc }}$ : section modulus of the combined section

$\mathrm{k}$ : $\quad$ confining adjustment factor

Appendix 2: Comparison of Finite Element Analysis and Theoretical Equation for Flexural Capacity for CFEST Members Bent around Long Axis

\begin{tabular}{cccccccc}
\hline $\begin{array}{c}2 a \\
(\mathrm{~mm})\end{array}$ & $\begin{array}{c}2 b \\
(\mathrm{~mm})\end{array}$ & $\begin{array}{c}t \\
(\mathrm{~mm})\end{array}$ & $\begin{array}{c}f_{\mathrm{ck}} \\
\left(\mathrm{N} / \mathrm{mm}^{2}\right)\end{array}$ & $\begin{array}{c}f_{\mathrm{y}} \\
\left(\mathrm{N} / \mathrm{mm}^{2}\right)\end{array}$ & $\begin{array}{c}M_{\mathrm{c}} \\
(\mathrm{kN} \times \mathrm{m})\end{array}$ & $\begin{array}{c}M_{\text {FEM }} \\
(\mathrm{kN} \times \mathrm{m})\end{array}$ & $\begin{array}{c}M_{\mathrm{c}} \\
M_{\text {FEM }}\end{array}$ \\
\hline 151.79 & 94.87 & 2.91 & 20.1 & 235 & 14.86 & 15.06 & 0.987 \\
161.00 & 89.44 & 2.87 & 20.1 & 235 & 15.20 & 15.80 & 0.962 \\
169.71 & 84.85 & 2.82 & 20.1 & 235 & 15.52 & 16.46 & 0.943 \\
151.79 & 94.87 & 2.91 & 26.8 & 235 & 15.55 & 15.70 & 0.990 \\
161.00 & 89.44 & 2.87 & 26.8 & 235 & 15.89 & 16.50 & 0.963 \\
169.71 & 84.85 & 2.82 & 26.8 & 235 & 16.20 & 17.22 & 0.941 \\
151.79 & 94.87 & 2.91 & 20.1 & 345 & 21.34 & 20.92 & 1.020 \\
161.00 & 89.44 & 2.87 & 20.1 & 345 & 21.91 & 21.90 & 1.000 \\
151.79 & 94.87 & 2.91 & 32.4 & 235 & 16.16 & 16.19 & 0.998 \\
161.00 & 89.44 & 2.87 & 32.4 & 235 & 16.51 & 17.04 & 0.969 \\
169.71 & 84.85 & 2.82 & 20.1 & 345 & 22.44 & 22.78 & 0.985 \\
177.99 & 80.90 & 2.77 & 20.1 & 345 & 22.92 & 23.82 & 0.962 \\
185.90 & 77.46 & 2.72 & 20.1 & 345 & 23.37 & 24.78 & 0.943 \\
151.79 & 94.87 & 2.91 & 20.1 & 390 & 24.12 & 23.25 & 1.037 \\
161.00 & 89.44 & 2.87 & 20.1 & 390 & 24.81 & 24.33 & 1.020 \\
169.71 & 84.85 & 2.82 & 20.1 & 390 & 25.45 & 25.28 & 1.006 \\
177.99 & 80.90 & 2.77 & 20.1 & 390 & 26.03 & 26.43 & 0.985 \\
185.90 & 77.46 & 2.72 & 20.1 & 390 & 26.58 & 27.49 & 0.967 \\
193.49 & 74.42 & 2.67 & 20.1 & 390 & 27.09 & 28.41 & 0.954 \\
200.80 & 71.71 & 2.63 & 20.1 & 390 & 27.58 & 29.16 & 0.946 \\
207.85 & 69.28 & 2.58 & 20.1 & 390 & 28.04 & 30.27 & 0.926
\end{tabular}




\begin{tabular}{llllllll}
141.99 & 101.42 & 3.94 & 20.1 & 345 & 26.74 & 25.02 & 1.069 \\
151.79 & 94.87 & 3.88 & 20.1 & 345 & 27.74 & 26.41 & 1.050 \\
161.00 & 89.44 & 3.82 & 20.1 & 345 & 28.64 & 27.70 & 1.034 \\
169.71 & 84.85 & 3.76 & 20.1 & 345 & 29.46 & 28.92 & 1.019 \\
177.99 & 80.90 & 3.69 & 20.1 & 345 & 30.22 & 30.02 & 1.007 \\
185.90 & 77.46 & 3.62 & 20.1 & 345 & 30.94 & 31.20 & 0.992 \\
193.49 & 74.42 & 3.56 & 20.1 & 345 & 31.61 & 32.12 & 0.984 \\
200.80 & 71.71 & 3.50 & 20.1 & 345 & 32.25 & 33.19 & 0.972 \\
207.85 & 69.28 & 3.43 & 20.1 & 345 & 32.86 & 34.30 & 0.958 \\
151.79 & 94.87 & 4.85 & 20.1 & 345 & 33.79 & 31.66 & 1.067 \\
161.00 & 89.44 & 4.77 & 20.1 & 345 & 35.08 & 33.16 & 1.058 \\
169.71 & 84.85 & 4.69 & 20.1 & 345 & 36.26 & 34.73 & 1.044 \\
177.99 & 80.90 & 4.61 & 20.1 & 345 & 37.37 & 36.05 & 1.037 \\
185.90 & 77.46 & 4.52 & 20.1 & 345 & 38.40 & 37.35 & 1.028 \\
193.49 & 74.42 & 4.44 & 20.1 & 345 & 39.38 & 38.65 & 1.019 \\
200.80 & 71.71 & 4.36 & 20.1 & 345 & 40.32 & 39.90 & 1.011 \\
207.85 & 69.28 & 4.28 & 20.1 & 345 & 41.22 & 41.11 & 1.003 \\
\hline
\end{tabular}

Appendix 3: Comparison of Finite Element Analysis and Theoretical Equation for Flexural Capacity for CFEST Members Bent around Short Axis

\begin{tabular}{|c|c|c|c|c|c|c|c|c|}
\hline $\begin{array}{c}2 a \\
(\mathrm{~mm})\end{array}$ & $\begin{array}{c}2 b \\
(\mathrm{~mm})\end{array}$ & $\begin{array}{c}t \\
(\mathrm{~mm})\end{array}$ & $\begin{array}{c}f_{\mathrm{ck}} \\
\left(\mathrm{N} / \mathrm{mm}^{2}\right)\end{array}$ & $\begin{array}{c}f_{\mathrm{y}} \\
\left(\mathrm{N} / \mathrm{mm}^{2}\right)\end{array}$ & $\begin{array}{c}x_{0} \\
(\mathrm{~mm})\end{array}$ & $\begin{array}{c}M_{\mathrm{c}} \\
(\mathrm{kN} \times \mathrm{m})\end{array}$ & $\begin{array}{c}M_{\mathrm{FEM}} \\
(\mathrm{kN} \times \mathrm{m})\end{array}$ & $\frac{M_{\mathrm{c}}}{M_{\mathrm{FEM}}}$ \\
\hline 131.45 & 109.54 & 2.99 & 20.1 & 235 & 22.64 & 11.57 & 13.19 & 1.004 \\
\hline 169.71 & 84.85 & 2.82 & 20.1 & 235 & 26.42 & 9.09 & 16.46 & 0.993 \\
\hline 200.80 & 71.71 & 2.63 & 20.1 & 235 & 29.28 & 7.76 & 19.08 & 0.987 \\
\hline 207.85 & 69.28 & 2.58 & 20.1 & 235 & 29.99 & 7.50 & 19.81 & 0.977 \\
\hline 131.45 & 109.54 & 2.99 & 26.8 & 235 & 26.05 & 11.96 & 13.71 & 1.001 \\
\hline 141.99 & 101.42 & 2.96 & 26.8 & 235 & 27.42 & 11.13 & 14.69 & 0.998 \\
\hline 151.79 & 94.87 & 2.91 & 26.8 & 235 & 28.77 & 10.42 & 15.70 & 0.986 \\
\hline 161.00 & 89.44 & 2.87 & 26.8 & 235 & 29.88 & 9.87 & 16.50 & 0.987 \\
\hline 169.71 & 84.85 & 2.82 & 26.8 & 235 & 30.98 & 9.39 & 17.22 & 0.989 \\
\hline 177.99 & 80.90 & 2.77 & 26.8 & 235 & 32.01 & 8.97 & 18.07 & 0.981 \\
\hline 185.90 & 77.46 & 2.72 & 26.8 & 235 & 32.99 & 8.60 & 18.84 & 0.976 \\
\hline 193.49 & 74.42 & 2.67 & 26.8 & 235 & 33.94 & 8.27 & 19.50 & 0.975 \\
\hline 200.80 & 71.71 & 2.63 & 26.8 & 235 & 34.74 & 8.00 & 20.05 & 0.980 \\
\hline 207.85 & 69.28 & 2.58 & 26.8 & 235 & 35.64 & 7.73 & 20.84 & 0.970 \\
\hline 207.85 & 69.28 & 2.58 & 32.4 & 235 & 39.70 & 7.89 & 21.64 & 0.963 \\
\hline 131.45 & 109.54 & 2.99 & 20.1 & 345 & 19.03 & 16.39 & 18.42 & 1.017 \\
\hline 141.99 & 101.42 & 2.96 & 20.1 & 345 & 19.78 & 15.26 & 19.65 & 1.014 \\
\hline 185.90 & 77.46 & 2.72 & 20.1 & 345 & 22.92 & 11.84 & 24.78 & 1.000 \\
\hline 193.49 & 74.42 & 2.67 & 20.1 & 345 & 23.48 & 11.40 & 25.61 & 1.000 \\
\hline 185.90 & 77.46 & 2.72 & 20.1 & 390 & 21.72 & 13.28 & 27.49 & 1.008 \\
\hline 193.49 & 74.42 & 2.67 & 20.1 & 390 & 22.25 & 12.79 & 28.41 & 1.008 \\
\hline 200.80 & 71.71 & 2.63 & 20.1 & 390 & 22.52 & 12.36 & 29.16 & 1.014 \\
\hline 207.85 & 69.28 & 2.58 & 20.1 & 390 & 23.20 & 11.96 & 30.27 & 1.005 \\
\hline 131.45 & 109.54 & 3.98 & 20.1 & 345 & 16.32 & 20.96 & 23.37 & 1.024 \\
\hline 141.99 & 101.42 & 3.94 & 20.1 & 345 & 16.89 & 19.53 & 25.02 & 1.018 \\
\hline 185.90 & 77.46 & 3.62 & 20.1 & 345 & 19.41 & 15.20 & 31.20 & 1.015 \\
\hline
\end{tabular}




\begin{tabular}{lllllllll}
\hline 193.49 & 74.42 & 3.56 & 20.1 & 345 & 19.82 & 14.66 & 32.12 & 1.020 \\
200.80 & 71.71 & 3.50 & 20.1 & 345 & 20.24 & 14.17 & 33.19 & 1.019 \\
151.79 & 94.87 & 4.85 & 20.1 & 345 & 15.23 & 22.19 & 31.66 & 1.024 \\
161.00 & 89.44 & 4.77 & 20.1 & 345 & 15.69 & 21.02 & 33.16 & 1.026 \\
169.71 & 84.85 & 4.69 & 20.1 & 345 & 16.10 & 20.04 & 34.73 & 1.023 \\
177.99 & 80.90 & 4.61 & 20.1 & 345 & 16.49 & 19.19 & 36.05 & 1.026 \\
185.90 & 77.46 & 4.52 & 20.1 & 345 & 16.97 & 18.42 & 37.35 & 1.026 \\
193.49 & 74.42 & 4.44 & 20.1 & 345 & 17.39 & 17.76 & 38.65 & 1.026 \\
200.80 & 71.71 & 4.36 & 20.1 & 345 & 17.82 & 17.16 & 39.90 & 1.026 \\
207.85 & 69.28 & 4.28 & 20.1 & 345 & 18.28 & 16.62 & 41.11 & 1.025 \\
\hline
\end{tabular}

Appendix 4: Comparison of Finite Element Analysis and Theoretical Equation for CFEST Members under Eccentric Compression around Long Axis

\begin{tabular}{|c|c|c|c|c|c|c|c|c|}
\hline $\begin{array}{c}2 a \\
(\mathrm{~mm})\end{array}$ & $\begin{array}{c}2 b \\
(\mathrm{~mm})\end{array}$ & $\begin{array}{c}t \\
(\mathrm{~mm})\end{array}$ & $\begin{array}{c}L \\
(\mathrm{~mm})\end{array}$ & $\lambda$ & $\begin{array}{c}e_{0} \\
(\mathrm{~mm})\end{array}$ & $\begin{array}{c}N \\
(\mathrm{kN})\end{array}$ & $\begin{array}{c}M \\
(\mathrm{kN} \times \mathrm{m})\end{array}$ & $\begin{array}{c}\text { Interaction } \\
\text { equation }\end{array}$ \\
\hline 141.99 & 101.42 & 2.96 & 1000 & 39.44 & 5 & 411.66 & 2.06 & 1.001 \\
\hline 141.99 & 101.42 & 2.96 & 1000 & 39.44 & 10 & 365.14 & 3.65 & 1.023 \\
\hline 141.99 & 101.42 & 2.96 & 1000 & 39.44 & 50 & 180.26 & 9.01 & 1.031 \\
\hline 141.99 & 101.42 & 2.96 & 1000 & 39.44 & 60 & 156.85 & 9.41 & 1.010 \\
\hline 141.99 & 101.42 & 2.96 & 1000 & 39.44 & 70 & 138.14 & 9.67 & 0.990 \\
\hline 141.99 & 101.42 & 2.96 & 1000 & 39.44 & 80 & 122.98 & 9.84 & 0.970 \\
\hline 141.99 & 101.42 & 2.96 & 1000 & 39.44 & 90 & 110.90 & 9.98 & 0.955 \\
\hline 141.99 & 101.42 & 2.96 & 1000 & 39.44 & 200 & 51.62 & 10.32 & 0.972 \\
\hline 141.99 & 101.42 & 2.96 & 1000 & 39.44 & 300 & 34.57 & 10.37 & 0.980 \\
\hline 141.99 & 101.42 & 2.96 & 1000 & 39.44 & 400 & 25.97 & 10.39 & 0.983 \\
\hline 141.99 & 101.42 & 2.96 & 1000 & 39.44 & 500 & 20.81 & 10.40 & 0.986 \\
\hline 141.99 & 101.42 & 2.96 & 1000 & 39.44 & 600 & 17.37 & 10.42 & 0.988 \\
\hline 141.99 & 101.42 & 2.96 & 1000 & 39.44 & 700 & 14.91 & 10.43 & 0.990 \\
\hline 141.99 & 101.42 & 2.96 & 1000 & 39.44 & 800 & 13.06 & 10.45 & 0.992 \\
\hline 141.99 & 101.42 & 2.96 & 1000 & 39.44 & 900 & 11.62 & 10.46 & 0.993 \\
\hline 141.99 & 101.42 & 2.96 & 1000 & 39.44 & 1000 & 10.47 & 10.47 & 0.994 \\
\hline 169.71 & 84.85 & 2.82 & 1000 & 47.14 & 5 & 375.22 & 1.88 & 0.988 \\
\hline 169.71 & 84.85 & 2.82 & 1000 & 47.14 & 10 & 325.95 & 3.26 & 0.999 \\
\hline 169.71 & 84.85 & 2.82 & 1000 & 47.14 & 15 & 288.90 & 4.33 & 1.009 \\
\hline 169.71 & 84.85 & 2.82 & 1000 & 47.14 & 20 & 260.83 & 5.22 & 1.022 \\
\hline 169.71 & 84.85 & 2.82 & 1000 & 47.14 & 25 & 236.73 & 5.92 & 1.028 \\
\hline 207.85 & 69.28 & 2.58 & 1000 & 57.74 & 900 & 8.63 & 7.77 & 0.991 \\
\hline 207.85 & 69.28 & 2.58 & 1000 & 57.74 & 1000 & 7.79 & 7.79 & 0.993 \\
\hline 169.71 & 84.85 & 2.82 & 1000 & 47.14 & 30 & 215.50 & 6.47 & 1.026 \\
\hline 169.71 & 84.85 & 2.82 & 1000 & 47.14 & 35 & 197.42 & 6.91 & 1.023 \\
\hline 169.71 & 84.85 & 2.82 & 1000 & 47.14 & 40 & 182.42 & 7.30 & 1.022 \\
\hline 169.71 & 84.85 & 2.82 & 1000 & 47.14 & 50 & 155.60 & 7.78 & 1.002 \\
\hline 169.71 & 84.85 & 2.82 & 1000 & 47.14 & 500 & 17.91 & 8.95 & 0.981 \\
\hline 169.71 & 84.85 & 2.82 & 1000 & 47.14 & 600 & 14.94 & 8.97 & 0.983 \\
\hline 169.71 & 84.85 & 2.82 & 1000 & 47.14 & 700 & 12.82 & 8.97 & 0.984 \\
\hline 169.71 & 84.85 & 2.82 & 1000 & 47.14 & 800 & 11.22 & 8.98 & 0.985 \\
\hline 169.71 & 84.85 & 2.82 & 1000 & 47.14 & 900 & 9.98 & 8.99 & 0.986 \\
\hline 169.71 & 84.85 & 2.82 & 1000 & 47.14 & 1000 & 9.02 & 9.10 & 1.000 \\
\hline
\end{tabular}




\begin{tabular}{lllllcccl}
\hline 185.90 & 77.46 & 2.72 & 1000 & 51.64 & 5 & 394.42 & 1.80 & 0.981 \\
185.90 & 77.46 & 2.72 & 1000 & 51.64 & 10 & 340.65 & 3.11 & 0.992 \\
185.90 & 77.46 & 2.72 & 1000 & 51.64 & 20 & 268.37 & 4.90 & 1.006 \\
185.90 & 77.46 & 2.72 & 1000 & 51.64 & 30 & 220.76 & 6.04 & 1.010 \\
185.90 & 77.46 & 2.72 & 1000 & 51.64 & 40 & 185.50 & 6.77 & 1.002 \\
185.90 & 77.46 & 2.72 & 1000 & 51.64 & 50 & 158.89 & 7.25 & 0.988 \\
185.90 & 77.46 & 2.72 & 1000 & 51.64 & 60 & 137.81 & 7.54 & 0.970 \\
185.90 & 77.46 & 2.72 & 1000 & 51.64 & 70 & 121.21 & 7.74 & 0.952 \\
185.90 & 77.46 & 2.72 & 1000 & 51.64 & 200 & 45.17 & 8.24 & 0.963 \\
185.90 & 77.46 & 2.72 & 1000 & 51.64 & 300 & 30.30 & 8.30 & 0.972 \\
185.90 & 77.46 & 2.72 & 1000 & 51.64 & 400 & 22.79 & 8.32 & 0.976 \\
185.90 & 77.46 & 2.72 & 1000 & 51.64 & 500 & 18.27 & 8.33 & 0.978 \\
185.90 & 77.46 & 2.72 & 1000 & 51.64 & 600 & 15.25 & 8.35 & 0.980 \\
185.90 & 77.46 & 2.72 & 1000 & 51.64 & 700 & 13.10 & 8.37 & 0.983 \\
185.90 & 77.46 & 2.72 & 1000 & 51.64 & 800 & 11.46 & 8.36 & 0.983 \\
185.90 & 77.46 & 2.72 & 1000 & 51.64 & 900 & 10.19 & 8.37 & 0.984 \\
185.90 & 77.46 & 2.72 & 1000 & 51.64 & 1000 & 9.18 & 8.38 & 0.984 \\
207.85 & 69.28 & 2.58 & 1000 & 57.74 & 5 & 342.73 & 1.71 & 0.977 \\
207.85 & 69.28 & 2.58 & 1000 & 57.74 & 10 & 292.18 & 2.92 & 0.980 \\
207.85 & 69.28 & 2.58 & 1000 & 57.74 & 20 & 228.25 & 4.57 & 0.993 \\
207.85 & 69.28 & 2.58 & 1000 & 57.74 & 30 & 185.83 & 5.57 & 0.991 \\
207.85 & 69.28 & 2.58 & 1000 & 57.74 & 40 & 155.62 & 6.22 & 0.982 \\
207.85 & 69.28 & 2.58 & 1000 & 57.74 & 50 & 132.42 & 6.62 & 0.965 \\
207.85 & 69.28 & 2.58 & 1000 & 57.74 & 200 & 37.77 & 7.55 & 0.958 \\
207.85 & 69.28 & 2.58 & 1000 & 57.74 & 300 & 25.41 & 7.62 & 0.969 \\
207.85 & 69.28 & 2.58 & 1000 & 57.74 & 400 & 19.14 & 7.66 & 0.974 \\
207.85 & 69.28 & 2.58 & 1000 & 57.74 & 500 & 15.37 & 7.69 & 0.979 \\
207.85 & 69.28 & 2.58 & 1000 & 57.74 & 600 & 12.85 & 7.71 & 0.982 \\
207.85 & 69.28 & 2.58 & 1000 & 57.74 & 700 & 11.05 & 7.73 & 0.985 \\
207.85 & 69.28 & 2.58 & 1000 & 57.74 & 800 & 9.69 & 7.75 & 0.988 \\
\hline & & & & & & & & \\
\hline
\end{tabular}

Appendix 5: Comparison of Finite Element Analysis and Theoretical Equation for CFEST Members under Eccentric Compression around Short Axis

\begin{tabular}{ccccccccc}
\hline $\begin{array}{c}2 a \\
(\mathrm{~mm})\end{array}$ & $\begin{array}{c}2 b \\
(\mathrm{~mm})\end{array}$ & $\begin{array}{c}t \\
(\mathrm{~mm})\end{array}$ & $\begin{array}{c}L \\
(\mathrm{~mm})\end{array}$ & $\lambda$ & $\begin{array}{c}e_{0} \\
(\mathrm{~mm})\end{array}$ & $\begin{array}{c}N \\
(\mathrm{kN})\end{array}$ & $\begin{array}{c}M \\
(\mathrm{kN} \times \mathrm{m})\end{array}$ & $\begin{array}{c}\text { Interaction } \\
\text { equation }\end{array}$ \\
\hline 131.45 & 109.54 & 2.99 & 1200 & 36.51 & 5 & 585.14 & 2.93 & 0.975 \\
131.45 & 109.54 & 2.99 & 1200 & 36.51 & 20 & 443.82 & 8.88 & 0.997 \\
131.45 & 109.54 & 2.99 & 1200 & 36.51 & 40 & 327.63 & 13.11 & 0.985 \\
131.45 & 109.54 & 2.99 & 1200 & 36.51 & 60 & 252.69 & 15.16 & 0.951 \\
131.45 & 109.54 & 2.99 & 1200 & 36.51 & 80 & 202.93 & 16.23 & 0.916 \\
131.45 & 109.54 & 2.99 & 1200 & 36.51 & 100 & 168.09 & 16.81 & 0.885 \\
131.45 & 109.54 & 2.99 & 1200 & 36.51 & 300 & 60.32 & 18.10 & 0.974 \\
131.45 & 109.54 & 2.99 & 1200 & 36.51 & 500 & 36.67 & 18.33 & 0.991 \\
131.45 & 109.54 & 2.99 & 1200 & 36.51 & 800 & 23.17 & 18.53 & 1.003 \\
141.99 & 101.42 & 2.96 & 1200 & 33.81 & 5 & 592.22 & 3.86 & 1.021 \\
141.99 & 101.42 & 2.96 & 1200 & 33.81 & 20 & 461.12 & 12.02 & 1.044 \\
141.99 & 101.42 & 2.96 & 1200 & 33.81 & 40 & 348.06 & 18.14 & 1.037 \\
141.99 & 101.42 & 2.96 & 1200 & 33.81 & 60 & 270.80 & 21.17 & 0.998 \\
\hline
\end{tabular}




\begin{tabular}{|c|c|c|c|c|c|c|c|c|}
\hline 141.99 & 101.42 & 2.96 & 1200 & 33.81 & 80 & 217.95 & 22.72 & 0.957 \\
\hline 141.99 & 101.42 & 2.96 & 1200 & 33.81 & 500 & 39.41 & 25.68 & 0.997 \\
\hline 141.99 & 101.42 & 2.96 & 1200 & 33.81 & 800 & 24.86 & 25.91 & 1.008 \\
\hline 151.79 & 94.87 & 2.91 & 1200 & 31.62 & 5 & 593.99 & 2.42 & 0.987 \\
\hline 151.79 & 94.87 & 2.91 & 1200 & 31.62 & 20 & 470.49 & 7.67 & 1.021 \\
\hline 151.79 & 94.87 & 2.91 & 1200 & 31.62 & 40 & 361.87 & 11.79 & 1.027 \\
\hline 151.79 & 94.87 & 2.91 & 1200 & 31.62 & 60 & 285.87 & 13.98 & 1.001 \\
\hline 151.79 & 94.87 & 2.91 & 1200 & 31.62 & 80 & 231.97 & 15.12 & 0.966 \\
\hline 151.79 & 94.87 & 2.91 & 1200 & 31.62 & 300 & 69.53 & 17.00 & 0.987 \\
\hline 151.79 & 94.87 & 2.91 & 1200 & 31.62 & 500 & 42.13 & 17.16 & 1.001 \\
\hline 151.79 & 94.87 & 2.91 & 1200 & 31.62 & 800 & 26.56 & 17.31 & 1.012 \\
\hline 161.00 & 89.44 & 2.87 & 1200 & 29.81 & 5 & 590.54 & 2.95 & 0.984 \\
\hline 161.00 & 89.44 & 2.87 & 1200 & 29.81 & 20 & 472.05 & 9.44 & 1.015 \\
\hline 161.00 & 89.44 & 2.87 & 1200 & 29.81 & 40 & 368.56 & 14.74 & 1.028 \\
\hline 161.00 & 89.44 & 2.87 & 1200 & 29.81 & 100 & 202.05 & 20.20 & 0.947 \\
\hline 161.00 & 89.44 & 2.87 & 1200 & 29.81 & 300 & 73.06 & 21.92 & 0.989 \\
\hline 161.00 & 89.44 & 2.87 & 1200 & 29.81 & 500 & 44.24 & 22.12 & 1.003 \\
\hline 161.00 & 89.44 & 2.87 & 1200 & 29.81 & 800 & 27.85 & 22.28 & 1.013 \\
\hline 169.71 & 84.85 & 2.82 & 1200 & 28.28 & 5 & 589.02 & 2.95 & 1.011 \\
\hline 169.71 & 84.85 & 2.82 & 1200 & 28.28 & 20 & 474.82 & 9.50 & 1.036 \\
\hline 169.71 & 84.85 & 2.82 & 1200 & 28.28 & 40 & 375.13 & 15.01 & 1.049 \\
\hline 169.71 & 84.85 & 2.82 & 1200 & 28.28 & 60 & 302.11 & 18.13 & 1.029 \\
\hline 169.71 & 84.85 & 2.82 & 1200 & 28.28 & 80 & 249.31 & 19.94 & 1.001 \\
\hline 169.71 & 84.85 & 2.82 & 1200 & 28.28 & 100 & 209.88 & 20.99 & 0.970 \\
\hline 169.71 & 84.85 & 2.82 & 1200 & 28.28 & 300 & 76.57 & 22.97 & 0.995 \\
\hline 169.71 & 84.85 & 2.82 & 1200 & 28.28 & 800 & 29.17 & 23.34 & 1.020 \\
\hline 177.99 & 80.90 & 2.77 & 1200 & 26.97 & 40 & 379.04 & 13.94 & 1.026 \\
\hline 177.99 & 80.90 & 2.77 & 1200 & 26.97 & 60 & 307.78 & 16.98 & 1.012 \\
\hline 177.99 & 80.90 & 2.77 & 1200 & 26.97 & 80 & 255.06 & 18.77 & 0.987 \\
\hline 177.99 & 80.90 & 2.77 & 1200 & 26.97 & 100 & 215.63 & 19.83 & 0.960 \\
\hline 177.99 & 80.90 & 2.77 & 1200 & 26.97 & 300 & 79.41 & 21.91 & 0.987 \\
\hline 177.99 & 80.90 & 2.77 & 1200 & 26.97 & 500 & 48.10 & 22.12 & 1.002 \\
\hline 177.99 & 80.90 & 2.77 & 1200 & 26.97 & 700 & 34.51 & 22.21 & 1.008 \\
\hline 177.99 & 80.90 & 2.77 & 1200 & 26.97 & 800 & 30.24 & 22.25 & 1.011 \\
\hline 185.90 & 77.46 & 2.72 & 1200 & 25.82 & 5 & 586.42 & 2.93 & 1.018 \\
\hline 185.90 & 77.46 & 2.72 & 1200 & 25.82 & 60 & 314.95 & 18.90 & 1.035 \\
\hline 185.90 & 77.46 & 2.72 & 1200 & 25.82 & 80 & 262.34 & 20.99 & 1.009 \\
\hline 185.90 & 77.46 & 2.72 & 1200 & 25.82 & 100 & 222.74 & 22.27 & 0.981 \\
\hline 185.90 & 77.46 & 2.72 & 1200 & 25.82 & 500 & 50.06 & 25.03 & 1.001 \\
\hline 193.49 & 74.42 & 2.67 & 1200 & 24.81 & 40 & 388.17 & 15.53 & 1.033 \\
\hline 193.49 & 74.42 & 2.67 & 1200 & 24.81 & 60 & 320.32 & 19.22 & 1.026 \\
\hline 193.49 & 74.42 & 2.67 & 1200 & 24.81 & 80 & 267.92 & 21.43 & 1.003 \\
\hline 193.49 & 74.42 & 2.67 & 1200 & 24.81 & 100 & 228.16 & 22.82 & 0.978 \\
\hline 193.49 & 74.42 & 2.67 & 1200 & 24.81 & 300 & 85.37 & 25.61 & 0.984 \\
\hline 193.49 & 74.42 & 2.67 & 1200 & 24.81 & 500 & 51.74 & 25.87 & 1.001 \\
\hline 193.49 & 74.42 & 2.67 & 1200 & 24.81 & 800 & 32.53 & 26.02 & 1.010 \\
\hline 200.80 & 71.71 & 2.63 & 1200 & 23.90 & 5 & 585.58 & 2.84 & 0.997 \\
\hline 200.80 & 71.71 & 2.63 & 1200 & 23.90 & 20 & 483.37 & 9.39 & 1.016 \\
\hline 200.80 & 71.71 & 2.63 & 1200 & 23.90 & 80 & 272.66 & 21.19 & 1.004 \\
\hline
\end{tabular}




\begin{tabular}{lcccccccc}
\hline 200.80 & 71.71 & 2.63 & 1200 & 23.90 & 100 & 232.85 & 22.62 & 0.980 \\
200.80 & 71.71 & 2.63 & 1200 & 23.90 & 300 & 87.74 & 25.57 & 0.982 \\
200.80 & 71.71 & 2.63 & 1200 & 23.90 & 800 & 33.43 & 25.99 & 1.009 \\
207.85 & 69.28 & 2.58 & 1200 & 23.09 & 5 & 586.52 & 2.93 & 1.013 \\
207.85 & 69.28 & 2.58 & 1200 & 23.09 & 20 & 486.68 & 9.73 & 1.028 \\
207.85 & 69.28 & 2.58 & 1200 & 23.09 & 80 & 278.69 & 22.30 & 1.014 \\
207.85 & 69.28 & 2.58 & 1200 & 23.09 & 100 & 238.93 & 23.89 & 0.991 \\
207.85 & 69.28 & 2.58 & 1200 & 23.09 & 300 & 90.78 & 27.23 & 0.980 \\
207.85 & 69.28 & 2.58 & 1200 & 23.09 & 800 & 34.60 & 27.68 & 1.008 \\
\hline
\end{tabular}

